\title{
The Effect of Grape Seed Extracts on Serum Paraoxonase Activities in Streptozotocin-Induced Diabetic Rats
}

\author{
Aysel Kıyıcı, Nilsel Okudan, ${ }^{2}$ Hakkı Gökbel, ${ }^{2}$ and Muaz Belviranlı ${ }^{2}$ \\ Departments of ${ }^{1}$ Biochemistry and ${ }^{2}$ Physiology, Meram Medical Faculty, Selcuk University, Konya, Turkey
}

\begin{abstract}
Procyanidins, a group of flavonoids, are oligomeric forms of catechins that are abundant in red wine, grapes, cocoa, and apples. Paraoxonase acts as an antioxidant enzyme and protects low-density lipoprotein-cholesterol against oxidation. In our study we aimed to evaluate the effects of grape seed extract (GSE) on paraoxonase activities in streptozotocin-induced diabetic rats. Our study included four groups of rats: Group I $(n=8)$, control; Group II $(n=10)$, GSE-supplemented; Group III $(n=6)$, streptozotocin-induced diabetic; and Group IV $(n=7)$, GSE-supplemented diabetic rats. Serum paraoxonase activities were determined with a spectrophotometric method. Paraoxonase activities in Group III were significantly lower than in the other three groups $(P<.001, P<.001$, and $P=.005$ for Groups I, II, and IV, respectively), and Group IV showed increased paraoxonase activities compared to Group III $(P=.005)$. This is the first study to show an association between paraoxonase status and GSE supplementation and demonstrated that GSE increased paraoxonase activities. This beneficial effect of GSE was more obvious in the diabetic group, which was more prone to atherosclerotic events compared to the healthy population.
\end{abstract}

KEY WORDS: ・ diabetes $\bullet$ grape seed extract $\bullet$ paraoxonase

\section{INTRODUCTION}

D iabetes Mellitus is an important systemic disease, based on the growing number of the affected population throughout the world. Diabetes is known as an independent risk factor for coronary artery disease, stroke, and peripheral arterial disease. Eighty percent of all deaths among the diabetic population result from atherosclerotic events. ${ }^{1}$ Prolonged hyperglycemia by means of the increased oxidative stress was suggested as the major cause of endothelial dysfunction, which plays a pivotal role in development of atherosclerosis. ${ }^{2,3}$

Procyanidins are flavonoids that are widely found in vegetables, cereals, and fruits like grapes, berries, cocoa, and apples. They are phenolic compounds-oligomeric forms of catechins-and are involved in many biological activities. ${ }^{4}$ They affect intracellular signal enzymes such as tyrosine kinases and phosphodiesterases. Not only being potential antioxidants either by their own antioxidant properties or by increasing plasma levels of some vitamins like ascorbate and tocopherol, but also with beneficial effects like plasma lipid- and lipid peroxide-lowering activity, induction of decrease in blood pressure, and dilatation of endothelium-dependent blood vessels, procyanidins are considered as cardioprotective agents. ${ }^{5,6}$ Grape seed extract

\footnotetext{
Manuscript received 7 November 2009. Revision accepted 3 February 2010.
}

Address correspondence to: Nilsel Okudan, Department of Physiology, Meram Medical Faculty, Selcuk University, Konya 42080, Turkey, E-mail: nokudan@ selcuk.edu.tr
(GSE) contains biologically active polyphenolic flavonoids that have been shown to be involved in many biological and pharmacological processes and have been used as therapeutic agents against oxidative stress. ${ }^{7,8}$

Paraoxonase (PON1) is a serum esterase that has the ability to hydrolyze paraoxon-the active metabolite of an organic phosphorus-containing insecticide, parathion. ${ }^{9,10}$ The enzyme also catalyzes the breakdown of some other organic phosphorus-containing insecticides, sarin and tabun gases, various carbamates, and many aromatic carboxylic acid esters like phenyl acetate, 4-nitrophenyl acetate, and 2-naphthyl acetate. ${ }^{11,12}$ PON1 is synthesized in the liver and is bound to plasma high-density lipoproteins (HDLs) in the circulation. This enzyme prevents the oxidation of lowdensity lipoproteins (LDLs) and acts as a protective enzyme against atherogenesis. It has two major activities against atherosclerotic process: it presents esterase activity upon hydrolysis of phospholipid hydroperoxides and cholesteryl ester hydroperoxides, and peroxidase activity upon the reduction of lipid hydroperoxides and degradation of hydrogen peroxide. PON1 provides beneficial effects against atherosclerosis by protection of HDL from peroxidation and plasma membranes from free radical injury. ${ }^{13}$

The impact of procyanidins and especially of GSE on diabetes and atherosclerosis has been studied, and some beneficial effects of these compounds against atherosclerosis have been reported. In our study we aimed to evaluate the effect of GSE on PON1 activities in streptozotocin-induced diabetic rats. 
Table 1. HDL-Cholesterol Concentrations and PON1 Activities

\begin{tabular}{|c|c|c|c|c|}
\hline Parameter & Control & GSE control & Diabetic & GSE diabetic \\
\hline$n$ & 8 & 10 & 6 & 7 \\
\hline HDL-cholesterol (mmol/L) & $0.518 \pm 0.178$ & $0.583 \pm 0.085$ & $0.720 \pm 0.137$ & $0.748 \pm 0.360$ \\
\hline PON1 (U/L) & $84.23 \pm 11.54$ & $102.29 \pm 23.43$ & $45.98 \pm 17.19^{\mathrm{abc}}$ & $86.34 \pm 21.83$ \\
\hline
\end{tabular}

${ }^{\mathrm{a}} P<.001$ versus control group.

${ }^{\mathrm{b}} P<.001$ versus GSE control group.

${ }^{\mathrm{c}} P=.005$ versus GSE diabetic group.

\section{MATERIALS AND METHODS}

The study protocol was approved by the Ethical Committee of the Selcuk University Experimental Medicine Research and Application Center (Konya, Turkey). This study was performed on 31 Sprague-Dawley male rats, which were 16 weeks old and weighed 200-300 g at the beginning of the experiment. All animals were housed in cages with $12 / 12$-hour light/dark cycle at $21^{\circ} \mathrm{C}$ and $50 \%$ humidity. Rats were randomly divided into four groups: Group I $(n=8)$, control; Group II $(n=10)$, GSE-supplemented control; Group III $(n=6)$, streptozotocin-induced diabetic; and Group IV $(n=7)$, GSE-supplemented diabetic. Streptozotocin was intraperitoneally administered at a dose of $50 \mathrm{mg} / \mathrm{kg}$ of body weight dissolved in saline. Tail vein blood glucose was measured 1 week after the injection of streptozotocin. The diabetic state was confirmed when the glucose concentration exceeded $300 \mathrm{mg} / \mathrm{dL}$. After that, Groups III and IV were formed. Rats in Groups II and IV were given GSE at $100 \mathrm{mg} / \mathrm{kg} /$ day with tap water for 6 weeks. The animals were given standard rat chow and tap water ad libitum. After 6 weeks, rats were sacrificed by cervical dislocation following intracardiac blood sampling under ketamine/xylazine anesthesia. Blood samples taken from the rats were centrifuged at $1,000 \mathrm{~g}$ for 10 minutes, and sera were stored at $-80^{\circ} \mathrm{C}$ until biochemical analysis.

GSE (ActiVin ${ }^{\circledR}$ ) was provided by Phil Castro from San Joaquin Concentrates (Fresno, CA, USA). IH636 (GSE) was extracted with a standardized water-ethanol mixture. IH636 contains dimeric proanthocyanidins (54\%), trimeric proanthocyanidins (13\%), tetrameric proanthocyanidins (7\%), monomeric proanthocyanidins (less than 5\%), and other flavonoids. Antioxidants like cathechins and oligomeric proanthocyanidins also occur in this extract. Polysaccharides $(10.8 \%)$, proteins $(2.1 \%)$, phytosterols $(0.5 \%)$, fatty acids (2.8\%), and water (5-6\%) are the other components of IH636.

HDL-cholesterol levels were determined by the direct enzymatic method without precipitation (Randox, Crumlin, UK) on a Synchron LX20 system (Beckman Coulter, Fullerton, CA, USA). PON1 enzyme activities were determined with a spectrophotometric method described as previously. ${ }^{14}$ In brief, PON1 activity toward paraoxon (diethyl-p-nitrophenyl phosphate) was determined by measuring the initial rate of substrate hydrolysis to $p$ nitrophenol, and the difference in absorbance was monitored at $412 \mathrm{~nm}$. The enzyme activity was calculated from the absorbance at $412 \mathrm{~nm}$ of $p$-nitrophenol $\left(18,290 M^{-1} \mathrm{~cm}^{-1}\right)$ and was expressed as $\mathrm{U} / \mathrm{L}$.

\section{Statistical analysis}

SPSS for Windows (version 15.0) (SPSS, Inc., Chicago, IL) was used for statistical evaluation of the data. All data are presented as mean \pm SD values. Analysis of variance and Tukey's HSD test were used for comparison between groups. $P$ values of $<.05$ were considered significant.

\section{RESULTS}

PON1 activities and HDL-cholesterol concentrations of the groups are given in Table 1. There was no significant difference among the groups for HDL-cholesterol concentrations. PON1 activity of Group III was significantly lower than those of the other groups $(P<.001, P<.001$, and $P=.005$ for Groups I, II, and IV, respectively). GSE-supplemented diabetic rats also had significantly increased PON1 activities compared to the diabetic rats $(P=.005)$ (Fig. 1).

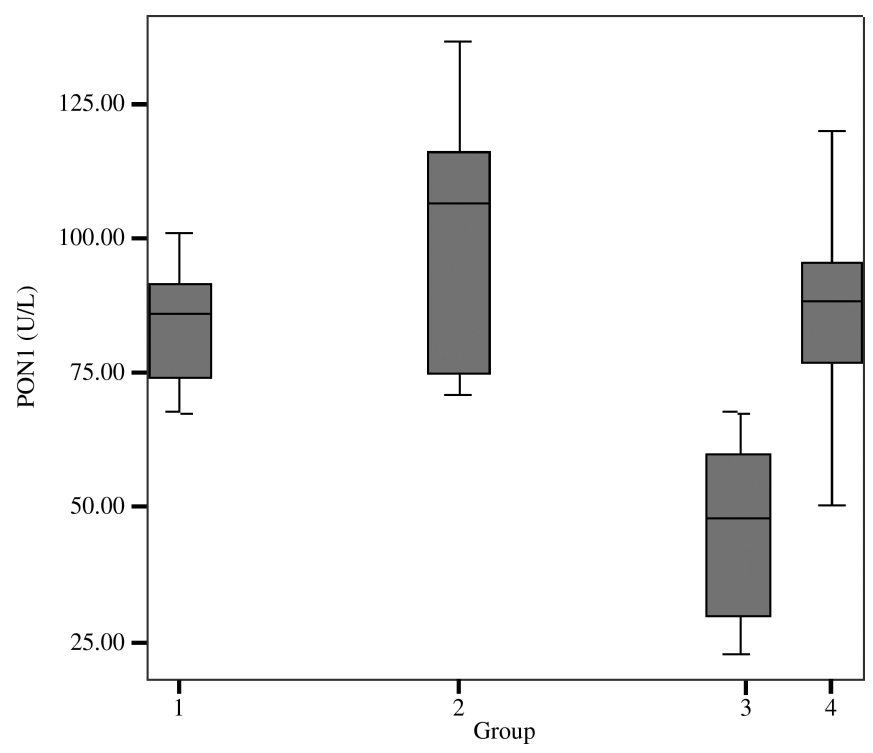

FIG. 1. PON1 activities of the experimental groups: 1, Group I, control; 2, Group II, GSE-supplemented; 3, Group III, diabetic; and 4, Group IV, GSE-supplemented diabetic. PON1 activities decreased significantly in Group III. Group IV showed also increased PON1 activities compared to Group III. 


\section{DISCUSSION}

This is the first study to show an association between PON1 status and GSE supplementation and demonstrate that GSE increases PON1 activity. This beneficial effect of GSE was more obvious in the diabetic group, which was more prone to atherosclerotic events compared to the healthy population. PON1, which protects LDL against in vitro oxidation, plays an important role in the beneficial effects of HDL on lipid peroxidation and the atherosclerotic process. ${ }^{15}$ It has been shown that PON1 enzymatic activity is decreased in coronary artery disease and ischemic stroke patients. ${ }^{16-19}$ Reduced PON1 activity was suggested to play a role in the severity of coronary atherosclerosis, and this relation was also shown in the diabetic group. ${ }^{20,21}$ PON1 activities were found to be significantly decreased in the diabetic group compared to other groups. ${ }^{22,23}$ An inverse correlation between PON1 enzymatic activity and the severity of coronary heart disease in a cross-sectional study of type 2 diabetic subjects was observed by Lakshman et al. ${ }^{24}$ Low concentration and enzymatic activity of PON1 were suggested to be independent predictors of cardiovascular events in diabetic patients. ${ }^{25}$ Recently, decreased PON1 and arylesterase activities were observed in women with gestational diabetes. ${ }^{26}$

The procyanidins have been the subject of research, especially for their antioxidant roles and protective effects on vascular endothelium. Its rich content of flavonoids has made GSE one of the most popular procyanidins for investigators. GSE was shown to have more potent free radical scavenger activity than vitamins E and C. ${ }^{27}$ Procyanidinrich extract from grape seed attenuates development of atherosclerosis in rabbits, and this result was supported by demonstrating its inhibitory effects on LDL oxidation in vitro when added to the incubation mixture. ${ }^{28,29} \mathrm{GSE}$ supplementation provided improvement in plasma antioxidant capacity and lipid profile in hypercholesterolemic subjects. ${ }^{30}$ Significantly reduced oxidized LDL and inhibition of endothelial CD36 expression, improved flowmediated dilatation shown ultrasonically, and decreased arterial pressure in hypertensive rats are some of the observed protective effects of GSE against atherosclerosis. ${ }^{31-34}$ Antihyperglycemic effects of GSE were also observed in diabetic rats. ${ }^{4}$ GSE has also been shown to have protective effects against high glucose-induced cytotoxicity. ${ }^{35}$

In the previous studies dealing with the protective effects of GSE against atherosclerosis, the researchers mostly showed the antioxidative effects of GSE and concluded that its anti-atherosclerotic properties depend on this powerful antioxidant potential. ${ }^{16-19}$ However, there is no research on the relation between GSE with an endogenous antioxidant and cardioprotective enzyme (PON1) as a coronary heart disease risk factor in either healthy or diabetic population. In this study we have observed decreased PON1 activities in streptozotocin-induced diabetic rats. This result was in agreement with previous data. ${ }^{22-26}$ GSE supplementation increased PON1 activity in control and diabetic rats, and this effect was more obvious in the diabetic group. Because re- duced PON1 activity was suggested to play a role in the severity of coronary atherosclerosis, especially in diabetics, ${ }^{21-24}$ and low concentration and enzymatic activity of PON1 were thought to be independent predictors of cardiovascular events in diabetic patients in a recent study, ${ }^{25}$ this beneficial effect of GSE on PON1 activity seems to be an important finding. This effect may be one of the antiatherosclerotic activities of GSE, and protection of LDL against oxidation by GSE may also be related to its inducing effect on PON1. Because our results show a more obvious increase in PON1 activities in GSE-supplemented diabetic rats, we concluded that GSE supplementation becomes more relevant in the diabetic population, who are more prone to atherosclerotic events.

We determined similar HDL-cholesterol concentrations in all groups. Our result is in agreement with the data of Vigna et al. ${ }^{36}$ and Preuss et al., ${ }^{37}$ who also did not observe any changes in HDL-cholesterol levels with GSE supplementation.

This study is the first experimental investigation of the effects of GSE on PON1 activity in streptozotocininduced diabetic rats. We concluded that PON1 activity decreases in diabetes and that GSE supplementation ameliorates PON1 activity in diabetic rats. This finding suggests that GSE supplementation may be beneficial for diabetic patients with decreased PON1 activity to make them less susceptible to coronary heart diseases. However, further investigations on the effect of GSE supplementation in healthy and diabetic humans are needed to support this suggestion.

\section{AUTHOR DISCLOSURE STATEMENT}

The authors have declared no conflict of interest.

\section{REFERENCES}

1. Wattanakit K, Folsom AR, Selvin E, Weatherley BD, Pankow JS, Brancati FL, Hirsch AT: Risk factors for peripheral arterial disease incidence in persons with diabetes: the Atherosclerosis Risk in Communities (ARIC) Study. Atherosclerosis 2005;180: 389-397.

2. Ceriello A, Motz E: Is oxidative stress the pathogenic mechanism underlying insulin resistance, diabetes, and cardiovascular disease? The common soil hypothesis revisited. Arterioscler Thromb Vasc Biol 2004;24:816-823.

3. Martin-Gallan P, Carrascosa A, Gussinye M, Dominguez C: Biomarkers of diabetes-associated oxidative stress and antioxidant status in young diabetic patients with or without subclinical complications. Free Radic Biol Med 2003;34:1563-1574.

4. Pinent M, Blay M, Blade MC, Salvado MJ, Arola L, Ardevol A: Grape seed-derived procyanidins have an antihyperglycemic effect in streptozotocin-induced diabetic rats and insulinomimetic activity in insulin-sensitive cell lines. Endocrinology 2004;145: 4985-4990.

5. Williamson G, Manach C: Bioavailability and bioefficacy of polyphenols in humans. II. Review of 93 intervention studies. Am J Clin Nutr 2005;81(1 Suppl):243S-255S.

6. Bagchi D, Bagchi M, Stohs SJ, Das DK, Ray SD, Kuszynski CA, Joshi SS, Preuss HG: Free radicals and grape seed proanthocyanidin 
extract: importance in human health and disease prevention. Toxicology 2000;148:187-197.

7. Bagchi D, Garg A, Krohn RL, Bagchi M, Tran MX, Stohs SJ: Oxygen free radical scavenging abilities of vitamins $\mathrm{C}$ and $\mathrm{E}$, and a grape seed proanthocyanidin extract in vitro. Res Commun Mol Pathol Pharmacol 1997;93:179-189.

8. Sato M, Maulik G, Ray PS, Bagchi D, Das DK: Cardioprotective effects of grape seed proanthocyanidin against ischemic reperfusion injury. J Mol Cell Cardiol 1999;31:1289-1297.

9. Juretic D, Tadijanovic M, Rekic B, Simean-Rudolf V, Reiner E, Baricic M: Serum paraoxonase activities in hemodialyzed uremic patients: cohort study. Clin Sci 2001;42:146-150.

10. Li WF, Costa LG, Furlong CE: Serum paraoxonase status: a major factor in determining resistance to organophosphates. J Toxicol Environ Health 1993;40:337-346.

11. Primo-Parma SL, Sorenson RC, Teiber J, La Du BN: The human serum paraoxonase/arylesterase gene (PON1) is one member of multigene family. Genomics 1996;33:498-509.

12. Mackness MI, Mackness B, Durrington PN, Connelly PW, Hegele RA: Paraoxonase: biochemistry, genetics and relationship to plasma lipoproteins. Curr Opin Lipidol 1996;7:69-76.

13. Durrington PN, Mackness B, Mackness MI: Paraoxonase and atherosclerosis. Arterioscler Thromb Vasc Biol 2001;21:473-480.

14. Eckerson HW, Wyte MC, La Du BN: The human serum paraoxonase/arylesterase polymorphism. Am J Hum Genet 1983;35: 1126-1138.

15. Mackness MI, Arrol S, Abbott C, Durrington PN: Protection of low-density lipoprotein against oxidative modification by highdensity lipoprotein associated paraoxonase. Atherosclerosis 1993; 104:129-135.

16. Ayub A, Mackness MI, Arrol S, Mackness B, Patel J, Durrington PN: Serum paraoxonase after myocardial infarction. Arterioscler Thromb Vasc Biol 1999;19:330-335.

17. Mohamed RH, Mohamed RH, Karam RA, Abd El-Aziz TA: The relationship between paraoxonase1-192 polymorphism and activity with coronary artery disease. Clin Biochem 2010;43: 553-558.

18. Kim NS, Kang K, Cha MH, Kang B-J, Moon J, Kang BK, Yu BC, Kim Y-S, Choi SM, Bang O-S: Decreased paraoxonase-1 activity is a risk factor for ischemic stroke in Koreans. Biochem Biophys Res Commun 2007;364:157-162.

19. Can Demirdogen B, Turkanoglu A, Bek S, Sanisoglu Y, Demirkaya S, Vural O, Arınc E, Adalı O: Paraoxonase/arylesterase ratio, PON1 192Q/R polymorphism and PON1 status are associated with increased risk of ischemic stroke. Clin Biochem 2008;41:1-9.

20. Gur M, Aslan M, Yildiz A, Yilmaz R, Selek S, Erel O, Ozdogru I: Paraoxonase and arylesterase activities in coronary artery disease. Eur J Clin Invest 2006;36:779-787.

21. Tartan Z, Orhan G, Kasıkçioglu H, Uyarel H, Unal S, Ozer N, Ozay B, Ciloglu, F, Cam N: The role of paraoxonase (PON) enzyme in the extent and severity of the coronary artery disease in type-2 diabetic patients. Heart Vessels 2007;22:158-164.

22. Inoue M, Suehiro T, Nakamura T, Ikeda Y, Kumon Y, Hashimoto K: Serum arylesterase/diazoxonase activity and genetic polymorphisms in patients with type 2 diabetes. Metabolism 2000;49:1400-1405.

23. Mackness B, Mackness MI, Arrol S, Turkie W, Julier K, Abuasha B, Miller JE, Boulton AJM, Durrington PN: Serum paraoxonase (PON1) 55 and 192 polymorphism and paraoxonase activity and concentration in non-insulin dependent diabetes mellitus. Atherosclerosis 1998;139:341-349.

24. Lakshman MR, Gottipati CS, Narasimhan SJ, Munoz J, Marmillot P, Nylen ES: Inverse correlation of serum paraoxonase and homocysteine thiolactonase activities and antioxidant capacity of high-density lipoprotein with the severity of cardiovascular disease in persons with type 2 diabetes mellitus. Metabolism 2006;55:1201-1206.

25. Ikeda Y, Inoue M, Suehiro T, Arii K, Kumon Y, Hashimoto K: Low human paraoxonase predicts cardiovascular events in Japanese patients with type 2 diabetes. Acta Diabetol 2009;46:239242.

26. Camuzcuoglu H, Toy H, Cakir H, Celik H, Erel O: Decreased paraoxonase and arylesterase activities in the pathogenesis of future atherosclerotic heart disease in women with gestational diabetes mellitus. J Womens Health (Lanchmt) 2009;18:14351439.

27. Bagchi D, Garg A, Krohn RL, Bagchi M, Tran MX, Stohs SJ: Oxygen free radical scavenging abilities of vitamin $\mathrm{C}$ and $\mathrm{E}$, and a grape seed proanthocyanidin extract in vitro. Res Commun Mol Pathol Pharmacol 1997;95:179-189.

28. Yamakoshi J, Kataoka S, Koga T, Ariga T: Proanthocyanidin rich extract from grape seeds attenuates the development of aortic atherosclerosis in cholesterol-fed rabbits. Atherosclerosis 1999; 142:421-422.

29. Mazur A, Bayle D, Lab C, Rock E, Rayssiguier Y: Inhibitory effect of procyanidin-rich extracts on LDL oxidation in vitro. Atherosclerosis 1999; 145:421-422.

30. Vinson J, Proch J, Bose P: MegaNatural ${ }^{\circledR}$ gold grapeseed extract: in vitro antioxidant and in vivo human supplementation studies. J Med Food 2001;4:17-26.

31. Bagchi D, Sen CK, Ray SD, Bagchi M, Preuss HG, Vinson JA: Molecular mechanisms of cardioprotection by a novel grape seed proanthocyanidin extract. Mutat Res 2003;523-524:87-97.

32. Clifton PM: Effect of grape seed extract and quercetin on cardiovascular and endothelial parameters in high-risk subjects. J Biomed Biotechnol 2004;2004:272-278.

33. Peng N, Clark JT, Prasain J, Kim H, White CR, Wyss JM: Antihypertensive and cognitive effects of grape polyphenols in estrogen-depleted, female, spontaneously hypertensive rats. Am J Physiol Regul Integr Comp Physiol 2005;289:R771-R775.

34. Kar P, Laight D, Shaw KM, Cummings MH: Flavonoid-rich grapeseed extracts: a new approach in high cardiovascular risk patients? Int J Clin Pract 2006;60:1484-1492.

35. Fujii H, Yokozawa T, Kim YA, Tohda C, Gen-ichiro N: Protective effect of grape seed polyphenols against high glucose induced oxidative stress. Biosci Biotechnol Biochem 2006;70: 2104-2111.

36. Vigna GB, Costantini F, Aldini G, Carini M, Catapano A, Schena F, Tangerini A, Zanca R, Bombardelli E, Morazzoni P, Mezzetti A, Fellin R, Maffei Facino R: Effect of a standardized grape seed extract on low-density lipoprotein susceptibility to oxidation in heavy smokers. Metabolism 2003;52:1250-1257.

37. Preuss HG, Wallerstedt D, Talpur N, Tutuncuoglu SO, Echard B, Myers A, Bui M, Bagchi D: Effects of niacin-bound chromium and grape seed proanthocyanidin extract on the lipid profile of hypercholesterolemic subjects: a pilot study. J Med 2000;31: 227-247. 